\title{
Anxiety \& Depression Assessment of cancer patients undergoing Chemotherapy or Radiotherapy Treatment by the use of computerized developed version of Questionnaire (WHOQOL-Bref, ZSAS, ZSDS)
}

\author{
Article by Kavita Gupta \\ Ph.D. Clinical Research, Texila American University, India \\ E-mail: 16kavitagupta@texilaconnect.com
}

\begin{abstract}
Background: The quality of life of cancer patients during chemotherapy sessions or radiotherapy sessions encompasses several changes. However, patient had to suffer a lot during the sessions. In order to, measure their quality of life through manual way, it is advisable to implement the computerized electronic version of QLQ so that the patient could deal with the different questions independently without hesitation that might led to increase in cognitive ability during the sessions. Moreover, the healthcare professionals could direct and plan the treatment accordingly so as to improve the QOL of cancer patients.

Objectives: The overarching purpose of this study had been to evaluate the acceptability of QOL assessments among healthcare professionals and cancer patients, by addressing how QOL assessments could be utilized to predict anxiety and depression scores, and by revealing how technology could contribute to the accuracy of QOL assessments and facilitate their implementation into oncology practices. The introduction of the electronic version of the QLQ could however, benefit the overall QOL of patients by bridging the gap between research and clinical practice among Indian population.

Methods: It was a cross-sectional, descriptive, hospital based evaluation study. Total duration of the study was 5 months (December 2015- April 2016), conducted in Medical and Radiation Oncology department of Dr. B.L. Kapur Memorial Hospital, New Delhi, India. A convenience sample of 60 patients with cancer was selected. They were further divided into Chemotherapy group $(n=30)$ and Radiotherapy group $(n=30)$. Data was obtained through direct interview, using validated Psychological intervention tool in the form of Questionnaire: WHOQOL-Bref Questionnaire, Zung Self-Rating Anxiety scale and Zung Self-Rating Depression scale, which was further managed through a statistical program, using appropriate statistical tests.

Results: A total of 60 cancer patients were included in the study in which Chemotherapy group consisted of 30n cancer patients and Radiotherapy group consisted of 30n cancer patients. In the study, 6(20\%) were males and 24(80\%) were females in the chemotherapy group, and, 15(50\%) were males and $15(50 \%)$ were females in the radiotherapy group. Majority of the patients 32(53.34\%) were in the age range of 46-60 years.

Conclusion: Utilizing technology to implement QOL assessments into clinical practice has several advantages that make it more feasible for physicians to use QOL information with their patients for predicting and determining anxiety and depression scores during cancer treatment. Electronic methods of assessment are more accurate and less time-consuming than paper-and pencil questionnaires (manual method).
\end{abstract}

Keywords: Cancer, Chemotherapy, Radiotherapy, Quality of Life, WHOQOL-Bref Questionnaire, Zung Self-Rating Anxiety scale, Zung Self-Rating Depression scale, Computerized QOL, Electronic version. 
Texila International Journal of Clinical Research

Volume 3, Issue 2, Dec 2016

$\begin{array}{ll}\text { Abbreviations } & \\ \text { QOL } & : \text { Quality of life } \\ \text { QLQ } & : \text { Quality life Questionnaire } \\ \text { WHOQOL-Bref } & : \text { World Health Organization Quality of life assessment-a short brief version } \\ \text { ZSAS } & : \text { Zung Self-Rating Anxiety scale } \\ \text { ZSDS } & : \text { Zung Self-Rating Depression scale } \\ \text { CT } & : \text { Chemotherapy Treatment } \\ \text { RT } & : \text { Radiotherapy Treatment } \\ \text { DOM } & : \text { Third Party Administrator } \\ \text { TPA } & : \text { Fine needle aspiration cytology } \\ \text { FNAC } & \text { Standard deviation. }\end{array}$

\section{Introduction}

QOL assessmentis an important aspect in cancer patients because they provide insights into life domains affected either by the symptoms of cancer-related or cancer-treatment related or both ${ }^{[1]}$. This knowledge is significant because many cancer patients stressed that quality of life was just as important, if not more important, than quantity of life ${ }^{[1]}$. QLQ serves as a communication evaluation tool in which assessment of records usually reflect the level of care given to a cancer patient by the physician and healthcare professionals ${ }^{[1]}$. In order to provide timely response to patients' needs, QOL should be embedded into the care process of patient reported outcomes by redesigning care, particularly by paying attention to principles of effective distribution as well as implementing new infrastructures and technologies ${ }^{[1]}$. Electronic version of QLQ record of cancer patients is a real-time, point-of-care, patient-centric information resource for clinicians that represent a major domain of health information technology (HIT) ${ }^{[1]}$. In order to have the ideal computerized assessment system, it must be clinically relevant (useful and presented in a timely manner), sensitive to change, culturally sensitive, low burden, low in cost, built into the standard operating procedures, and meet regulatory, consumer, and community requirements ${ }^{[1]}$. The effort that physicians take to inquire about QOL improves doctor-patient communication and shows patients that their physicians care about them and are interested in their well-being ${ }^{[1]}$. To patients, this is highly meaningful ${ }^{[1]}$.

\section{Aims}

The main objectives of the present study was:

i. To determine and evaluate the time duration in assessment of anxiety and depression scores for the assessment of quality of life in cancer patients by the use of WHOQOL-Bref, Zung Selfrating Anxiety Scale (ZSAS) and Zung Self Rating Depression Scale (ZSDS) questionnaire manually during chemotherapy treatment or radiotherapy treatment.

ii. To develop innovative electronic version (computerized assessment) of WHOQOL-Bref, ZSAS, and ZSDS Questionnaireto be implemented in the hospital in order to, evaluate quality of life in the cancer patients during chemotherapy treatment or radiotherapy treatment. 


\section{Patients and methods}

The proposed study was conducted in accordance and adherence to the Ethical Guidelines and Procedures. Special care of the potential risks due to emotional distress was taken care of so that the dignity of the subject was not harmed. The authorized Ethical approval from the IRB and Ethical committee of Dr. B.L. Kapur Memorial Hospital, New Delhi, with Ref. No.: IRB/AARCE/5/DEC/2015/1, dated December $7^{\text {th }}$, 2015, was obtained to carry out the research study. Thereafter, the patients and their caregivers were approached in the inpatient as well as, outpatient clinic, where the purpose of the study was explained and they were invited to participate. Patients who agreed to participate were asked to sign an Informed Consent Form followed by the implementation of the Structured and Validated instrumental tool of WHOQOL-Bref, Zung Self-Rating Anxiety Scale (ZSAS), and Zung Self-Rating Depression Scale (ZSDS) in the form of questionnaire which lasted for approximately 25-60 minutes. The RESEARCH DESIGN of the proposed approved study protocol included 30n cancer patients undergoing Chemotherapy Treatment and 30n cancer patients undergoing Radiotherapy Treatment session. The inclusion criteria for the approved study were the patients with Breast cancer, sub-sites of head and neck tumors (e.g., nasopharyngeal, thyroid cancer, and parotid tumors), aged 18 years or older, Clinically diagnosed and confirmed by biopsy or FNAC, Undergoing/during the treatment sessions ( $\geq 2$ cycles and $\leq 6$ for Chemotherapy treatment, and $\geq 10$ cycles and $\leq 30$ cycles for Radiotherapy treatment, Voluntarily agreed to join the study, and aware of diagnosis and predicted prognosis. However, the study excluded patients with Inadequate clinical condition (ambulatory and terminally ill patients) who were unable to respond to an interview, had difficulty in understanding the questionnaire or communicating, were serious and didn't give consent, had a history of psychiatric disorder. Moreover, the study did not include the dosage of chemotherapy drugs and irradiation treatment. Eligible patients were identified through an institutional database or by referring physicians and were approached at their simulation appointment.

\section{Results}

\section{(a) Data collection}

Treatment-related symptoms were assessed by using a series of interviews through standard questionnaires of WHOQOL-Bref, the core questionnaire, followed by Zung Self-Rating Anxiety Scale (ZSAS) and Zung Self Rating Depression Scale (ZSDS) Questionnaires. These questionnaires have been proven to have good validity and reliability properties, cross-culturally accepted instrument to measure Quality of Life in cancer patients and are publicly available for scholar research purposes $[2,3,4]$. The questionnaire was provided in a language that the patient could understand easily (English / Hindi) followed by face-to-face interview of the patient who was either undergoing chemotherapy or radiotherapy treatment sessions.

Parts of the Record Card:

i. Personal information form:This first part contained patient information. The form was prepared, based on the literature. It contained age, gender, qualification, marital status, family type, Occupation, data on financial income and site of tumor location ${ }^{[2]}$.

ii. WHOQOL-Bref Questionnaire: This is an abbreviated version of the instrument WHOQOL-100. It consisted of 26 questions, being two about quality of life in general and other 24 representing each of the facets that made up the original instrument ${ }^{[2]}$. The questions were organized in 4 domains:

a. Physical domain (DOM1): It included7 questions pertaining to sleep, energy, mobility, the extent to which pain prevents performance of necessary tasks, the need for medical treatment to function in daily life, level of satisfaction with their capacity for work ${ }^{[2]}$.

b. Psychological domain (DOM2): It included6 questions pertaining to the ability to concentrate, self-esteem, body image, spirituality i.e. the extent to which they feel their life is meaningful, the frequency of positive or negative feelings i.e. blue mood, despair, anxiety, depression ${ }^{[2]}$. 
Texila International Journal of Clinical Research

Volume 3, Issue 2, Dec 2016

c. Social domain (DOM3): It included 3 questions pertaining to satisfaction with personal relationships, social support systems and sexual satisfaction ${ }^{[2]}$.

d. Environmental domain (DOM4): It included 8 questions related to safety and security, home and physical environment satisfaction, finance i.e. does the respondent have enough money to meet their needs, health/social care availability, information and leisure activity accessibility and transportation satisfaction ${ }^{[2]}$.

Equations for computing domain raw scores:

Domain 1 (Physical) score = (6- Q3) + (6-Q4) + Q5 + Q6 + Q7 + Q8 + Q9

Domain 2 (Psychological) score = Q10 + Q11 + Q12 + Q13 + Q14 + (6-Q15)

Domain 3 (Social) score $=\mathrm{Q} 16+\mathrm{Q} 17+\mathrm{Q} 18$

Domain 4 (Environmental) score = Q19 + Q20 + Q21 + Q22 + Q23 + Q24 + Q25 + Q26 ${ }^{[2]}$.

In addition to the 4 domains, the WHOQOL-Bref included two stand-alone questions, one pertaining to the respondents' rated QOL, and one related to their Satisfaction with Health were analyzed separately ${ }^{[2]}$. The score of each question ranged from 1 to 5 on a 5 point likert scale and higher scores indicated a better evaluation. Raw scores of the respective domains were then transformed from 0-100 with the lowest score of zero and the highest score of 100according to the accepted guidelines.

iii. ZSAS: Zung Self-Rating Anxiety scale quality life questionnaire is a likert scale format (scoring on 1 to 4 scale) that was built by a psychiatrist, William W. K. Zung to measure the rate of anxiety. The scale consisted of 20 self-reported items with 15 questions of increasing anxiety level and 5 questions of decreasing anxiety level (Q. no. 5, 9, 13, 17, 19) ${ }^{[3]}$. Scores for each question ranged from 1 to 4 and higher scores indicated severe anxiety level. The raw scores were counted up and multiplied by 1.25 to reach a standardized score, according to the instructions that accompanied the scale ${ }^{[3]}$. The ZSAS Index score followed the crierion: Normal Range (20-44); Mild to Moderate Anxiety level (45-59); Marked to Severe Anxiety level (60-74); Extreme Anxiety level (75-80) ${ }^{[3]}$.

iv. ZSDS: Zung Self-Rating Depression scale quality life questionnaire is also a 20 items short self-administered survey that was designed by William W. K. Zung to assess the level of four common characteristics of depression for patients: the pervasive effect, the physiological equivalents, other disturbances, and psychomotor activities. There were ten positively worded and ten negatively worded questions. Each question was scored on a scale of 1-4 (a little of the time, some of the time, good part of the time, most of the time) ${ }^{[4]}$. The higher scores indicated severe depression level. The raw scores were counted up and multiplied by 1.25 to reach a standardized score, according to the instructions that accompanied the scale ${ }^{[4]}$. The ZSDS Index score followed the crierion: Normal Range $(<50)$; Mild Depression level $(<60)$; Moderate Depression level $(<70)$; Extreme Depression level $(>70){ }^{[4]}$.

\section{(b) Statistical analyses}

The database and statistical analysis was performed by using SPSS v.17 software. The independent variables analyzed were Socio-demographic characteristics (sex/gender, age, education level, marital status, employment type, income level (per annum), job background, local residence), Clinical characteristics (smoking habit, drinking habit, tobacco use, health insurance, tumor type \& location, metastasis involved, corresponding cycle number for both chemotherapy and radiotherapy treatment); Anxiety and Depression of the patients as assessed by ZSAS and ZSDS respectively. The dependent variables included: subscale and overall QOL scores, and Health satisfaction as measured by WHOQOL-Bref Questionnaire (Tool/instrument). Descriptive statistics computation techniques were applied to the discrete and continuous data. Measures such as mean, standard deviation, minimum and maximum range were developed from the continuous data. Relative frequency was calculated for discrete data. Mean with Standard deviation (SD) was used to summarize the age of patients. Chisquare test was performed to assess the effect of different sociodemographic factors and clinical characteristics on the QOL of the cancer patients. Student's $t$-test was used to compare sample means 
for study variables (anxiety, depression and QOL). Bivariate analysis was performed to assess the predictors of QOL. Based on the survey/ research, Pearson Correlation coefficient test denoted by $r$ was calculatedto assess the particular characteristic symptomatic function of anxiety and depression instrument that significantly affected the QOL domains, i.e., either positively or negatively. Paired ttest was used to compare difference between score means of different domains. A $p$-value $<0.05$ was considered as statistical significant.

\section{Socio-Demographic characteristics of the patients}

Table 1. Socio-demographic characteristics in the form of Frequency and percentage of variables of the patients and correlation in the two groups, i.e., Chemotherapy and Radiotherapy

\begin{tabular}{|c|c|c|c|c|c|c|}
\hline \multirow[t]{2}{*}{ S.No } & \multirow[t]{2}{*}{ Variables } & \multirow[t]{2}{*}{ Parameters } & \multicolumn{2}{|c|}{ Chemotherapy } & \multicolumn{2}{|c|}{ Radiotherapy } \\
\hline & & & $\begin{array}{l}\text { Frequency } \\
\text { (n) }\end{array}$ & $\begin{array}{l}\text { Percentage } \\
\text { (\%) }\end{array}$ & $\begin{array}{l}\text { Frequency } \\
\text { (n) }\end{array}$ & $\begin{array}{l}\text { Percentage } \\
\text { (\%) }\end{array}$ \\
\hline 1. & Gender & $\begin{array}{l}\text { a. Male } \\
\text { b. Female }\end{array}$ & $\begin{array}{l}6 \\
24 \\
\end{array}$ & $\begin{array}{l}20.0 \% \\
80.0 \%\end{array}$ & $\begin{array}{l}15 \\
15\end{array}$ & $\begin{array}{l}50.0 \% \\
50.0 \%\end{array}$ \\
\hline 2. & Age & $\begin{array}{l}\text { a. } 18-30 \text { years } \\
\text { b. } 30 \\
\text { c. } 46 \\
\text { d. } 60\end{array}$ & $\begin{array}{l}5 \\
17 \\
8\end{array}$ & $\begin{array}{l}16.7 \% \\
56.7 \% \\
26.7 \%\end{array}$ & $\begin{array}{l}6 \\
15 \\
9\end{array}$ & $\begin{array}{l}20.0 \% \\
50.0 \% \\
30.0 \%\end{array}$ \\
\hline 3. & $\begin{array}{l}\text { Marital } \\
\text { status }\end{array}$ & $\begin{array}{l}\text { a. Unmarried } \\
\text { b. Married } \\
\text { c. Widow } \\
\text { d. Divorced/ } \\
\quad \text { Legally } \\
\text { separated } \\
\text { e. Others }\end{array}$ & 30 & $100.0 \%$ & $\begin{array}{l}1 \\
28 \\
1\end{array}$ & $\begin{array}{l}3.3 \% \\
93.3 \% \\
3.3 \%\end{array}$ \\
\hline 4. & $\begin{array}{l}\text { Educational } \\
\text { status }\end{array}$ & $\begin{array}{l}\text { a. Illiterate } \\
\text { b. Literate }\end{array}$ & 1 & $3.3 \%$ & 2 & $6.7 \%$ \\
\hline & & $\begin{array}{l}\text { i. Primary } \\
\text { ii. Secondary } \\
\text { iii.Tertiary }\end{array}$ & $\begin{array}{l}4 \\
10 \\
15\end{array}$ & $\begin{array}{l}13.3 \% \\
33.3 \% \\
50.0 \%\end{array}$ & $\begin{array}{l}5 \\
11 \\
12\end{array}$ & $\begin{array}{l}16.7 \% \\
36.7 \% \\
40.0 \%\end{array}$ \\
\hline 5. & Occupation & $\begin{array}{l}\text { a. Service } \\
\text { b. Business } \\
\text { c. Housewife } \\
\text { d. Freelancers } \\
\text { e. Pensioners } \\
\text { f. Domestic } \\
\quad \text { duties } \\
\text { g. Cultivation }\end{array}$ & $\begin{array}{l}3 \\
3 \\
21 \\
3\end{array}$ & $\begin{array}{l}10.0 \% \\
10.0 \% \\
70.0 \% \\
10.0 \%\end{array}$ & $\begin{array}{l}10 \\
2 \\
11 \\
1 \\
4 \\
1 \\
1\end{array}$ & $\begin{array}{l}33.3 \% \\
6.7 \% \\
36.7 \% \\
3.3 \% \\
13.3 \% \\
3.3 \% \\
3.3 \%\end{array}$ \\
\hline 6. & $\begin{array}{l}\text { Type of } \\
\text { family }\end{array}$ & $\begin{array}{l}\text { a. Nuclear } \\
\text { b. Joint }\end{array}$ & $\begin{array}{l}16 \\
14\end{array}$ & $\begin{array}{l}53.3 \% \\
46.7 \%\end{array}$ & $\begin{array}{l}9 \\
21\end{array}$ & $\begin{array}{l}30.0 \% \\
70.0 \%\end{array}$ \\
\hline 7. & Cohabitants & $\begin{array}{l}\text { a. Living } \\
\text { alone } \\
\text { b. Living with }\end{array}$ & 15 & $50.0 \%$ & 4 & $13.3 \%$ \\
\hline
\end{tabular}


Texila International Journal of Clinical Research

Volume 3, Issue 2, Dec 2016

\begin{tabular}{|l|l|l|l|l|l|l|} 
& & $\begin{array}{l}\text { partner } \\
\text { c. Living with } \\
\text { partner and } \\
\text { children } \\
\text { d. Living with } \\
\text { children }\end{array}$ & 14 & $3.3 \%$ & 5 & $16.67 \%$ \\
\hline 8. & $\begin{array}{l}\text { Annual } \\
\text { income }\end{array}$ & $\begin{array}{l}\text { a. NA } \\
\text { b. } \leq 20 \\
\text { c. } 20 \\
\text { d. } 30 \\
\text { e. } 41 \\
\text { f. } \geq 84\end{array}$ & 22 & $73.3 \%$ & 11 & $30.0 \%$ \\
\hline 9. & $\begin{array}{l}\text { Place of } \\
\text { residence }\end{array}$ & $\begin{array}{l}\text { a. Small town } \\
\text { b. Big town }\end{array}$ & 1 & 29 & $26.7 \%$ & 19 \\
\hline
\end{tabular}

(All tests were performed using Pearson $\chi 2$ test for association analysis)

\section{Clinical characteristics of the patients}

Table 2. Clinicalcharacteristics in the form of Frequency and percentage of variables of the patients and correlation in the two groups, i.e., Chemotherapy or Radiotherapy

\begin{tabular}{|c|c|c|c|c|c|c|}
\hline \multirow[t]{2}{*}{ S.No. } & \multirow[t]{2}{*}{ Variables } & \multirow[t]{2}{*}{ Parameters } & \multicolumn{2}{|c|}{ Chemotherapy } & \multicolumn{2}{|c|}{ Radiotherapy } \\
\hline & & & $\begin{array}{l}\text { Frequency } \\
\text { (n) }\end{array}$ & $\begin{array}{l}\text { Percentage } \\
\text { (\%) }\end{array}$ & $\begin{array}{l}\text { Frequency } \\
\text { (n) }\end{array}$ & $\begin{array}{l}\text { Percentage } \\
(\%)\end{array}$ \\
\hline 1. & $\begin{array}{l}\text { Smoking } \\
\text { habit }\end{array}$ & $\begin{array}{l}\text { a. Non-smoker } \\
\text { b. Ex-smoker }\end{array}$ & $\begin{array}{l}27 \\
3\end{array}$ & $\begin{array}{l}90.0 \% \\
10.0 \%\end{array}$ & $\begin{array}{l}27 \\
4\end{array}$ & $\begin{array}{l}90.0 \% \\
10.0 \%\end{array}$ \\
\hline 2. & $\begin{array}{l}\text { Drinking } \\
\text { habit }\end{array}$ & $\begin{array}{l}\text { a. Non-drinker } \\
\text { b. Ex-drinker }\end{array}$ & 30 & $100.0 \%$ & $\begin{array}{l}26 \\
4\end{array}$ & $\begin{array}{l}86.7 \% \\
13.3 \% \\
\end{array}$ \\
\hline 3. & $\begin{array}{l}\text { Tobacco } \\
\text { use }\end{array}$ & $\begin{array}{l}\text { a. Yes } \\
\text { b. No }\end{array}$ & $\begin{array}{l}1 \\
29\end{array}$ & $\begin{array}{l}3.3 \% \\
96.7 \%\end{array}$ & $\begin{array}{l}7 \\
23\end{array}$ & $\begin{array}{l}23.3 \% \\
76.7 \%\end{array}$ \\
\hline 4. & $\begin{array}{l}\text { Health } \\
\text { insurance }\end{array}$ & $\begin{array}{l}\text { a. Yes } \\
\text { b. No }\end{array}$ & $\begin{array}{l}23 \\
7 \\
\end{array}$ & $\begin{array}{l}76.7 \% \\
23.3 \% \\
\end{array}$ & $\begin{array}{l}19 \\
11 \\
\end{array}$ & $\begin{array}{l}63.3 \% \\
36.7 \% \\
\end{array}$ \\
\hline 5. & $\begin{array}{l}\text { Type of } \\
\text { health } \\
\text { insurance }\end{array}$ & $\begin{array}{l}\text { a. Government } \\
\text { medically } \\
\text { insured } \\
\text { b. TPA } \\
\text { c. Cash }\end{array}$ & $\begin{array}{l}10 \\
13 \\
7\end{array}$ & $\begin{array}{l}33.3 \% \\
43.3 \% \\
23.3 \%\end{array}$ & $\begin{array}{l}7 \\
11\end{array}$ & $\begin{array}{l}40.0 \% \\
23.3 \% \\
36.7 \%\end{array}$ \\
\hline 6. & $\begin{array}{l}\text { Support by } \\
\text { charity } \\
\text { organizatio } \\
n\end{array}$ & $\begin{array}{l}\text { a. Yes } \\
\text { b. No }\end{array}$ & 30 & $100.0 \%$ & 30 & $100 \%$ \\
\hline
\end{tabular}


Texila International Journal of Clinical Research

Volume 3, Issue 2, Dec 2016

\begin{tabular}{|c|c|c|c|c|c|c|}
\hline 7. & $\begin{array}{l}\text { Cancer } \\
\text { tumor } \\
\text { location }\end{array}$ & $\begin{array}{l}\text { a. Ca Breast } \\
\text { b. Ca Head } \\
\text { c. Ca Neck }\end{array}$ & $\begin{array}{l}1 \\
6\end{array}$ & $\begin{array}{l}76.7 \% \\
3.3 \% \\
20.0 \%\end{array}$ & $\begin{array}{l}5 \\
15\end{array}$ & $\begin{array}{l}33.3 \% \\
16.7 \% \\
50.0 \%\end{array}$ \\
\hline 8. & $\begin{array}{l}\text { Disease } \\
\text { acceptance }\end{array}$ & $\begin{array}{l}\text { a. Yes } \\
\text { b. No }\end{array}$ & $\begin{array}{l}23 \\
7\end{array}$ & $\begin{array}{l}76.7 \% \\
23.3 \%\end{array}$ & $\begin{array}{l}15 \\
15\end{array}$ & $\begin{array}{l}50.0 \% \\
50.0 \%\end{array}$ \\
\hline 9. & $\begin{array}{l}\text { Reproductiv } \\
\text { e age of } \\
\text { women }\end{array}$ & $\begin{array}{l}\text { a. Pre- } \\
\text { menopausal } \\
\text { b. Menopausal }\end{array}$ & $\begin{array}{l}10 \\
14\end{array}$ & $\begin{array}{l}33.3 \% \\
46.7 \%\end{array}$ & 6 & $\begin{array}{l}30.0 \% \\
20.0 \%\end{array}$ \\
\hline 10. & Cancer type & $\begin{array}{l}\text { a. } \text { Primary } \\
\text { cancer } \\
\text { b. } \text { Recurrent } \\
\text { cancer }\end{array}$ & 30 & $100.0 \%$ & 30 & $100.0 \%$ \\
\hline 11. & $\begin{array}{l}\text { Co- } \\
\text { existence of } \\
\text { metastasis }\end{array}$ & $\begin{array}{l}\text { a. Yes } \\
\text { b. No }\end{array}$ & 8 & $\begin{array}{l}26.7 \% \\
73.4 \%\end{array}$ & 30 & $100.0 \%$ \\
\hline 12. & $\begin{array}{l}\text { Chemothera } \\
\text { py's cycle } \\
\text { during the } \\
\text { interview of } \\
\text { QLQ }\end{array}$ & $\begin{array}{l}\text { a. } 1^{\text {st }} \\
\text { b. } 2^{\text {nd }} \\
\text { c. } 3^{\text {rd }} \\
\text { d. } 4^{\text {th }} \\
\text { e. } 5^{\text {th }} \\
\text { f. } 6^{\text {th }}\end{array}$ & $\begin{array}{l}2 \\
15 \\
6 \\
6 \\
1\end{array}$ & $\begin{array}{l}6.7 \% \\
50.0 \% \\
20.0 \% \\
20.0 \% \\
3.3 \%\end{array}$ & & \\
\hline 13 & $\begin{array}{l}\text { Radiotherap } \\
\text { y's cycle } \\
\text { during the } \\
\text { interview of } \\
\text { QLQ }\end{array}$ & $\begin{array}{l}\text { a. } 10^{\text {th }}-15^{\text {th }} \\
\text { b. } 16^{\text {th }}-20^{\text {th }} \\
\text { c. } 21^{\text {st }}-25^{\text {th }} \\
\text { d. } 26^{\text {th }} 30^{\text {th }}\end{array}$ & & & $\begin{array}{l}21 \\
3 \\
1\end{array}$ & $\begin{array}{l}70.0 \% \\
10.0 \% \\
3.3 \%\end{array}$ \\
\hline
\end{tabular}


Time requirement in QOL Assessment process by the WHOQOL-BREF, ZSAS, ZSDS in both the chemotherapy group $(n=30)$ and radiotherapy group $(n=30)$, manually

Table 3: Time taken in QOL assessment through Questionnaires manually in both the groups, i.e., Chemotherapy $(n=30)$, and Radiotherapy $(n=30)$.

\begin{tabular}{|l|l|l|}
\hline $\begin{array}{l}\text { Process (Chemotherapy: } \mathbf{n} \\
\text { = 30; Radiotherapy: } \mathbf{n}=\end{array}$ & \multicolumn{2}{|l|}{ Time in minutes } \\
\cline { 2 - 3 } 30) & Range & (Mean \pm S.D.) \\
\hline $\begin{array}{l}\text { Researcher instructed how } \\
\text { to answer the questionnaire } \\
(\mathrm{n}=60)\end{array}$ & 29 & $(49.16 \pm 6.38)$ \\
\hline $\begin{array}{l}\text { Questionnaire completion } \\
(\mathrm{n}=60)\end{array}$ & 29 & $(49.16 \pm 6.38)$ \\
\hline $\begin{array}{l}\text { Patient themselves (n= 5) } \\
(30)\end{array}$ & 2 & $(57.00 \pm 1.00)$ \\
\hline $\begin{array}{l}\text { Assisted by relatives/care- } \\
\text { giver (n=7) }\end{array}$ & 4 & $(47.14 \pm 1.46)$ \\
\hline $\begin{array}{l}\text { Interviewed by researcher } \\
(\mathrm{n}=55)\end{array}$ & $(45-49)$ & \\
\hline
\end{tabular}

It was observed that the time taken by the patient to complete the questionnaires (WHOQOL-Bref, ZSAS, and ZSDS) either by himself or assisted by the researcher or by the patient's care-giver was minimum 30 minutes and maximum 59 minutes. This indicated that the total 66 questions for QOL assessments was a big tedious process.

\section{System specification for maximum and effective execution of the task by the system, there are the hardware and software requirement}

Hardware Requirement: System unit, Monitor (VDU), Uninterrupted power supply (UPS), 1 GB RAM, CD Rom, Hard disk capacity of 5 MB, Printer

Software Requirement: Window XP operating system (7/ 8// 10), Microsoft access, Microsoft visual basic, Dot Net framework 4.5.

Data items: Name of the patient, Age of the patient, Name of spouse, Name of the caregiver, Marital status of the patient, Gender, Address, Occupation, Educational status, Monthly income, Telephone number, Department of hospital, Hospital record number, Date of admission, Date of discharge, Hospital referred from, Hospital referred to, Primary physician, Other physicians, Diagnostic procedures, Tumor location, Mode of Treatment, Date of Admission and Date of Discharge. 


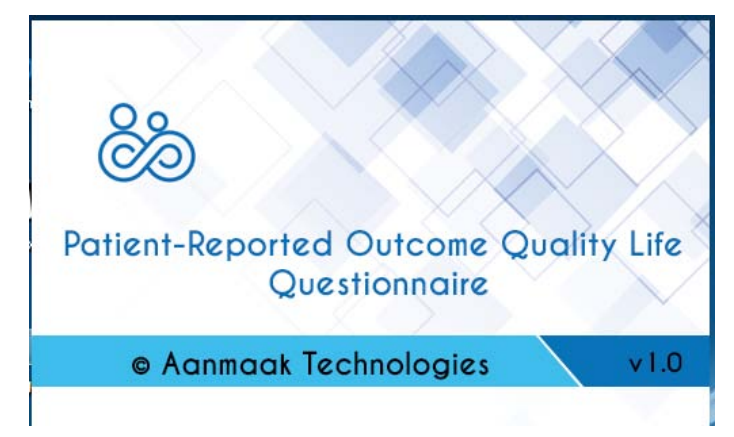

Fig. 1. Screenshot of the Software (Step 1)

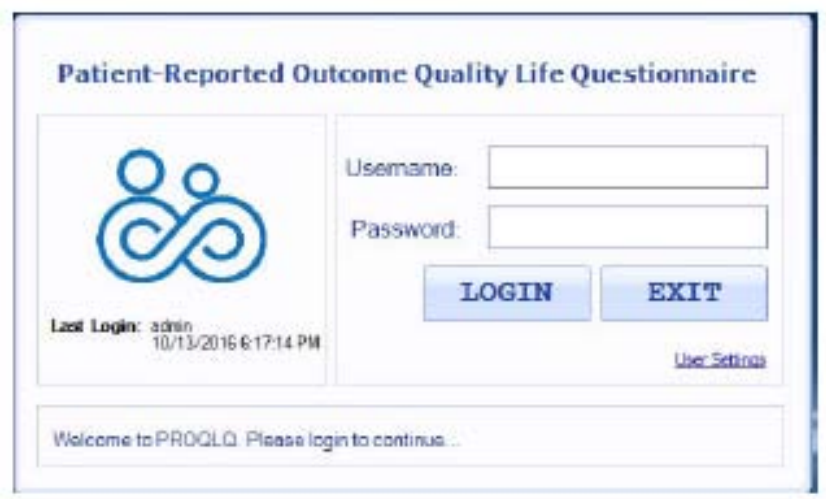

Fig. 2. Screenshot of the Software (Step 2)

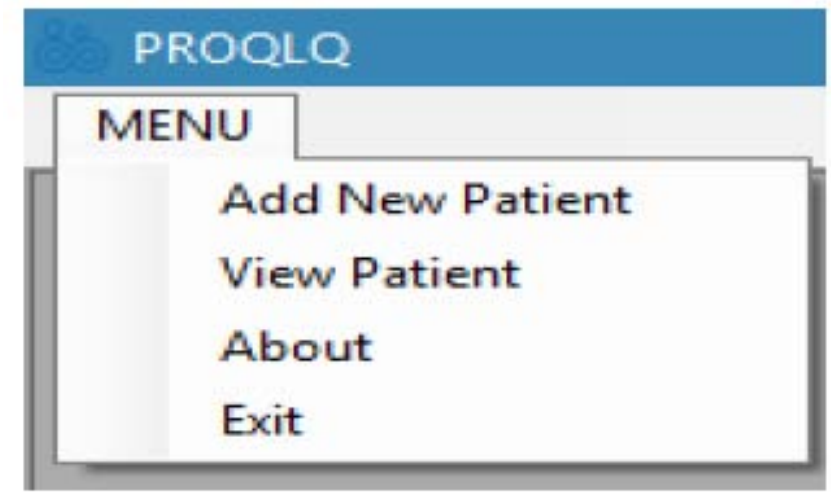

Fig. 3. Screenshot of the Software (Step 3)

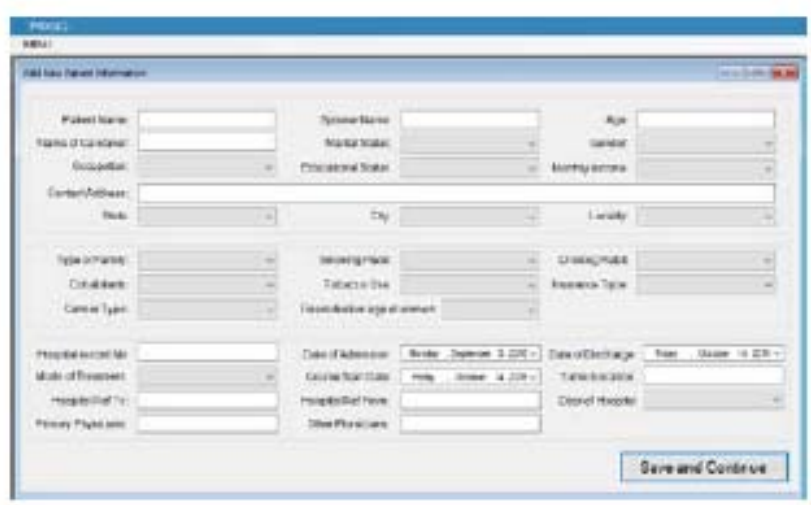


Texila International Journal of Clinical Research

Volume 3, Issue 2, Dec 2016

Fig. 4. Screenshot of the data items (Step 4)

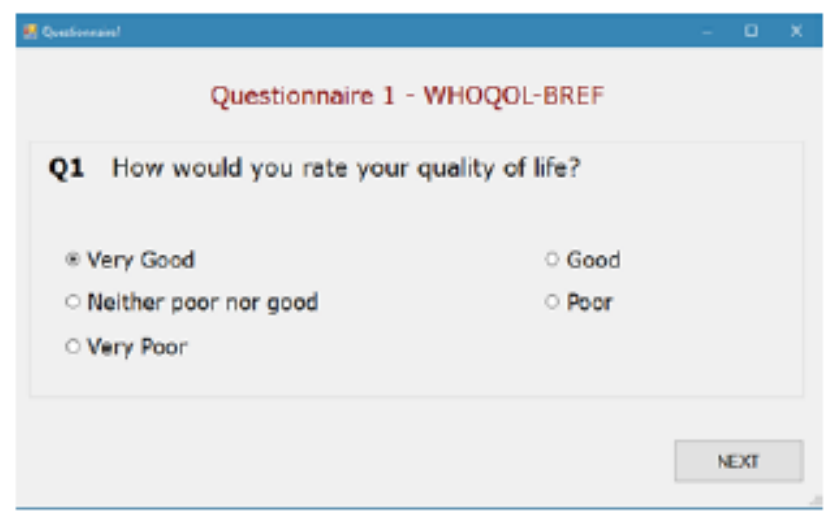

Fig. 5. Screenshot of the QLQ (Step 5)

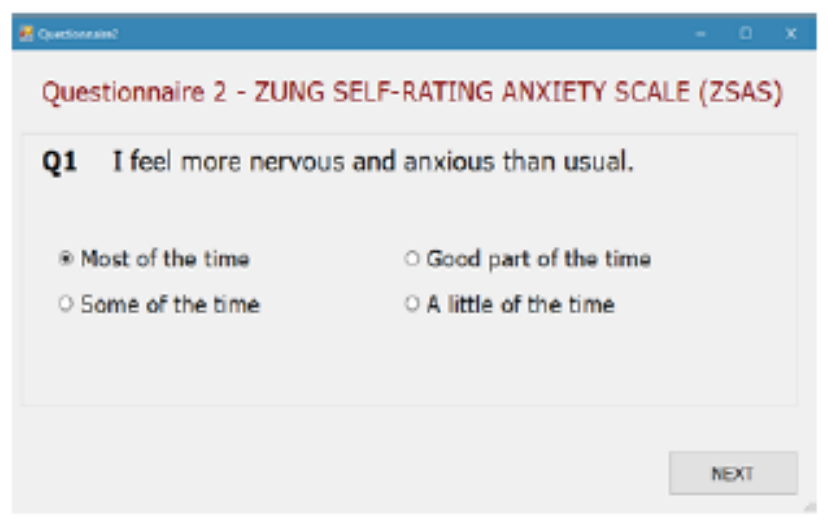

Fig. 6. Screenshot of the QLQ (Step 6)

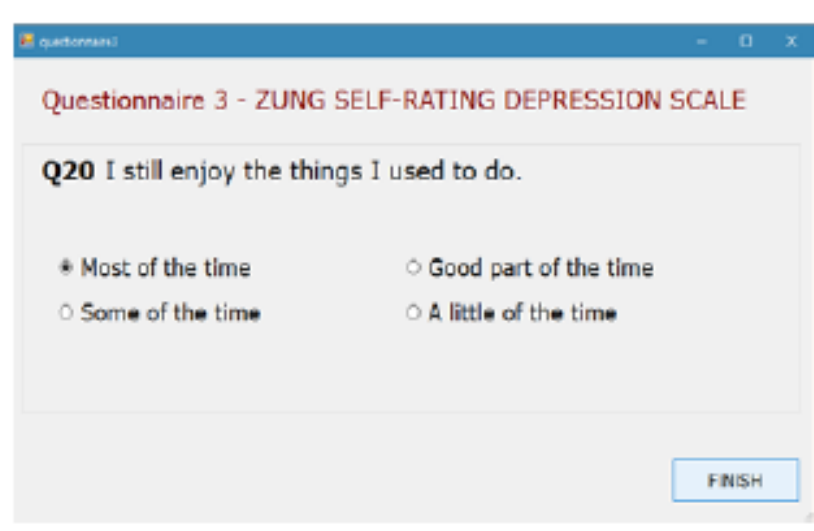

Fig. 7. Screenshot of the QLQ (Step 7) 


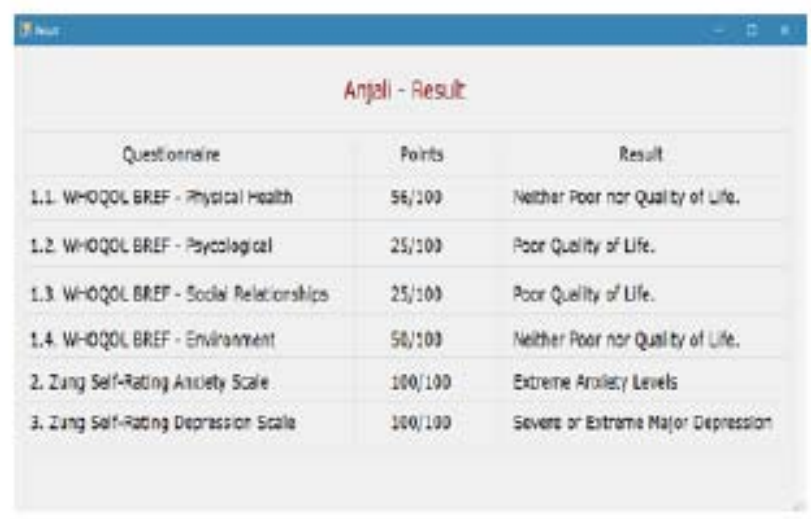

Fig. 8. Screenshot of the QLQ Result (Step 8)

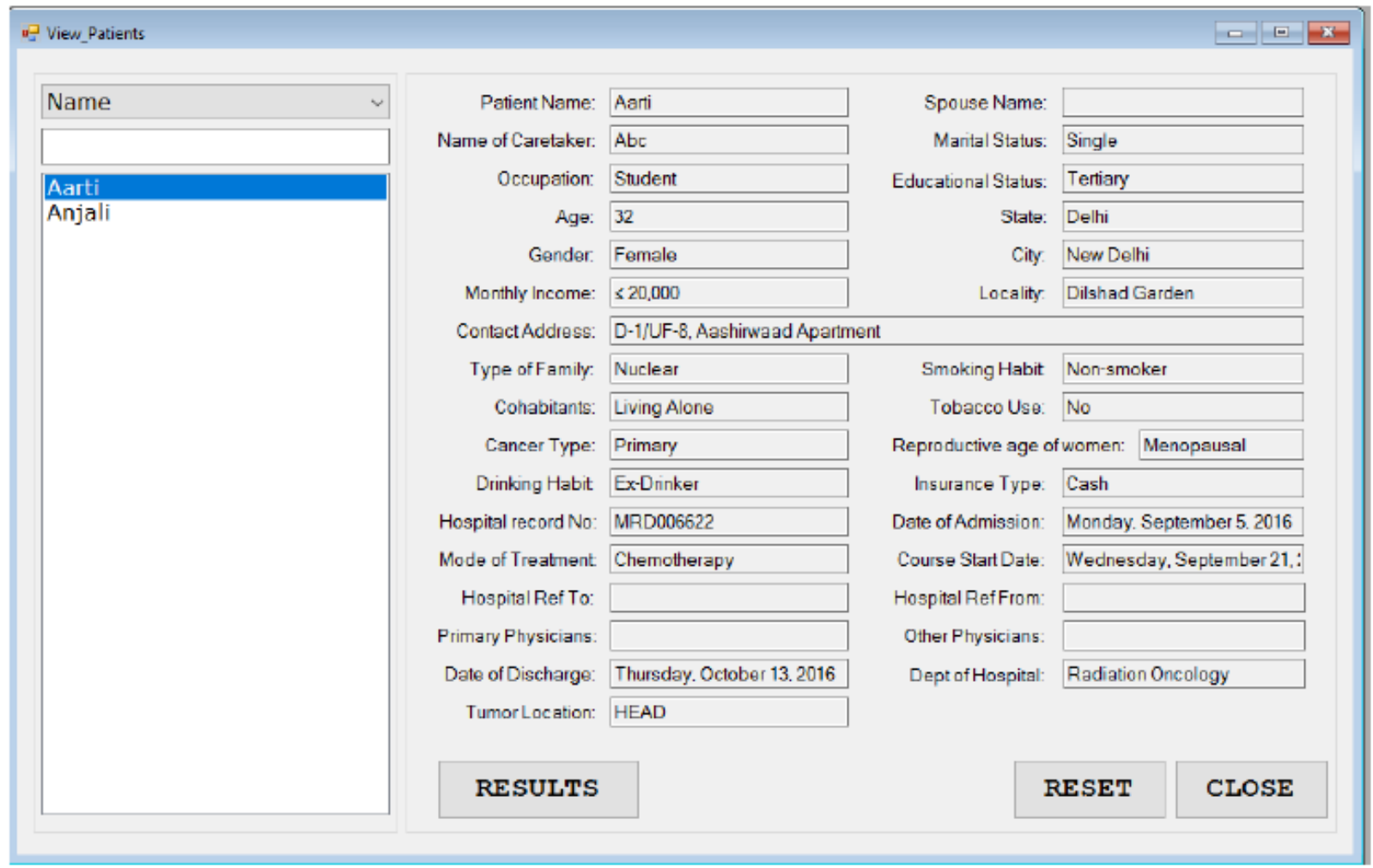

Fig. 9. Screenshot of the QLQ Saved data (Step 9)

\section{Discussion}

The time taken for QOL assessments in cancer patients manually was in a range : 30-59 (minutes). This required patience from the patients, as well as, the physician or healthcare professional. Since, the healthcare professionals and the physicians are very busy in the department because of workload as it was being estimated that there were only 1 doctor on 2000 patients in India. So, this ratio had a great impact on the patient's QOL during chemotherapy or radiotherapy treatment. The proposed computerized QOL could solve this problem upto a greater extent that involves patient's interest, full involvement, and ability to answer every question freely. On the other hand, physicians by looking at the filled form could easily analyze the factor affecting the most to the domains of QOL during cancer treatment and could plan accordingly with lessen time. Computerized QOL assessments had several advantages. They provided more accurate results, and as such, represent a picture of patients' QOL 
Texila International Journal of Clinical Research

Volume 3, Issue 2, Dec 2016

more clearly. Additionally, the use of technology to facilitate the implementation of QOL assessments increased the efficiency and allowed utilization by a wider population. Several studies have demonstrated the reasons why the implementation of computerized QOL assessments was found acceptable by physicians. According to a study by Buxton et al., a touch-screen computerized system had advantages over paper-and-pencil QOL questionnaires, which included the ability to increase the font size for those with visual difficulties, reduce the number of missed items, decrease the need for paper, analyze the patient's information immediately, and easily store and retrieve the data ${ }^{[1]}$. Allenby et al. reported that electronic completion of QOL questionnaires reduced the potential of errors with after-survey data input and can reduce the length of time it took to administer the questionnaires ${ }^{[1]}$. Taenzer et al. found patients took an average of 8.6 minutes to complete an electronic version of the EORTC QLQ-C30 questionnaire as opposed to 11 minutes to complete its paper version. In another study by Velikova et al. examining the difference between the electronic version of the EORTC QLQC30 and its paper version, patients took less time to complete the touch-screen version (8.3 minutes) as opposed to the paper version (9.6 minutes) ${ }^{[1]}$. Bliven et al. stated that the Internet allowed for the collection of patient-reported data at multiple locations, at frequent time intervals, and at little cost ${ }^{[1]}$. The key advantage of shifting to computer-based patient record was the opportunity to strengthen the link between the hospital records and management information system so that resources uses and quality of care could be analyzed using hospital database which increases physician efficiency and reduce costs, as well as promote standardization of care. QOL measures must be easily implemented into the medical office routine, requiring that they be short, easy to interpret, and not require intricate training or scoring. These assessments need to be acceptable to the patients and be able to produce reports in real time without disrupting busy clinics. Because of time constraints, patients, physicians, and office staff are not always willing to incorporate something new into their clinical routine. Providing interpretations and recommendations about available resources and the score may be helpful rather than just providing the physician with a functional status score.

Even though QOL information is clinically valuable, physicians often view it as providing "soft" data that does not permit "hard" measurement such as that obtained in the laboratory. Barriers to implementation could also arise due to the types of questions asked. Questions that are too personal, sensitive, or irrelevant are more likely to be omitted by respondents. For example, some questionnaires ask respondents about their careers. Pijls-Johannesma et al. reported that such questions are irrelevant in the elderly population, as many respondents were retired ${ }^{[1]}$.

\section{Conclusion}

In conclusion, it was observed that QOL assessment tools through computer assessments, had several advantages and were beneficial for cancer patients. The implementation of QOL assessments into clinical practice for cancer treatment has a high potential to benefit patients. Health-related quality of life has increasingly been an important factor to consider in the holistic treatment of cancer patients, and by providing accurate insights into anxiety, depression, and QOL through self-reported questionnaires, physicians would be better able to make treatment decisions. Technologies could provide a highly efficient and accurate means of implementing QOL assessments so that they can help a wider range of cancer patients. The advantages of implementing QOL tools are further supported by studies comparing intervention groups and controls, which have found that the intervention groups received more counseling and meaningful discussion with physicians. The information and advice gained in these counseling sessions have several benefits. In addition to learning about cancer, patients gain an understanding of how to best use the advice they received to improve the quality of their own lives. Because QOL instruments provide accurate assessments of the well-being and functionality of patients, utilizing them in clinical practice would significantly benefit patients and provide them with insights into their own care. This accurate, reliable and efficient method of computer based system generates the patient's QOL report and record as the patient register in and out of the hospital to ensure efficient outcome that will lessen time consuming. The development of 
electronic version of QLQ for measuring QOL of cancer patients which could enhance support to both the physicians and patient for better self-management, and improved adherence with chemotherapy and radiotherapy treatment. If successful, this intervention of electronic QLQ will be able to demonstrate and generate effects of Cancer and cancer treatment related effects on QOL of cancer patients that can be formally engaged to improve clinical outcomes.

Computerized version of QLQ could prove useful for evaluating cancer patients' experiences with hospitals that included the most important aspects regarding both inpatient and outpatient hospital care from the patient perspective. Eliciting feedback from patients helps healthcare providers to identify potential areas for improvement, which in turn can increase the quality of healthcare.

\section{Future directions}

Future studies involving the QOL of cancer patients should examine emerging science surrounding the implementation of QOL instruments, such as computerized versions. In order to create the most reliable and user-friendly application, potential users of the software should be included from the beginning to determine where possible problems might lie. Careful selection of the QOL assessment(s) should be considered with each population being examined to provide a reliable and valid patient-reported outcome.

\section{Limitations of the study}

1. The study did not implement the computerized version for the assessment, in fact, it was the outcome of the study, as the patients faced the difficulty while filling up the manual questionnaire.

2. To validate the electronic version, further cross-sectional study with large pool of sample size is required.

\section{Footnotes}

Author's Contribution: 1- acquisition of data; 2- analysis and interpretation of data; 3- drafting of the manuscript; 4- critical revision of the manuscript for important intellectual content; 5- statistical analysis; 6- administrative, technical and material supports, and software of QLQ- By Mr. Anant Gupta (Aanmaak Technologies (OPC) Pvt. Ltd., New Delhi).

Funding/Support: Self-funded.

\section{Acknowledgement}

The present study is a part of the research programme, "Assessment of Quality of Life of Adult Cancer Patients during inpatient Chemotherapy Treatment (CT), or outpatient Radiotherapy Treatment (RT) in a tertiary care hospital of New Delhi, India”. This research was supportedand assisted by at:

Department of Medical Oncology and Radiation Oncology, Dr. B.L. Kapur Memorial Hospital, New Delhi, India.

Under the Supervision of

Dr. S. Hukku (H.O.D. of Radiation Oncology Department),

Dr. B.L. Kapur Memorial Hospital,

New Delhi, India.

Dr. Amit Agarwal (H.O.D. of Medical Oncology Department),

Dr. B.L. Kapur Memorial Hospital,

New Delhi, India.

Under the Guidance of:

Dr. Renita Bhamrah (Texila American University),

E-mail:darpreetrenita@gmail.com 
Texila International Journal of Clinical Research

Volume 3, Issue 2, Dec 2016

\section{References}

[1]. Perry, S., Kowalski, T. L., \& Chang, C.-H. (2007). Quality of life assessment in women with breast cancer: benefits, acceptability and utilization. Health and Quality of Life Outcomes, 5, 24.

http://doi.org/10.1186/1477-7525-5-24

[2]. WHOQOL Group. (1998). Development of the World Health Organization WHOQOLBREF quality of life assessment. Psychol Med, 28:551-8.

[3]. Zung, W. W. K. (1971). A rating instrument for anxiety disorders. Psychosomatics, 12(6), 371-379. Available at: https://psychology-tools.com/zung-anxiety-scale/

[4]. Zung, W. W. K. (1965). A Self-Rating Depression Scale. (1965). Arch Gen Psychiatry, 12: 63-70. Available at: https://psychology-tools.com/zung-depression-scale/ 